\title{
Reverse Logistics and Competitive Advantage: The Mediating Effect of Operational Performance Among Manufacturing Firms in Kenya
}

\author{
Mwanyota L. Job, PhD Candidate \\ Prof. Muranga Njihia, Associate Professor \\ Management Science Department, School of Business, \\ University of Nairobi, Kenya \\ Prof. Jackson Maalu, Associate Professor \\ Department of Business Administration, School of Business, \\ University of Nairobi, Kenya \\ Prof. X.N. Iraki, Associate Professor \\ Management Science Department, School of Business, \\ University of Nairobi, Kenya
}

Doi:10.19044/esj.2020.v16n19p217 URL:http://dx.doi.org/10.19044/esj.2020.v16n19p217

\begin{abstract}
Today globally, countries and manufacturing entities alike are concerned with environmental sustainability apart from economic gains. Implementation of reverse logistics programs has been contemplated as a feasible alternative to mitigate the negative environmental effects of manufacturing while gaining competitory position. Literature has also suggested that improved operational performance results in the achievement of competitiveness. However the question has been whether implementing reverse logistics creates comparative advantage that leads to gaining competitive advantage for manufacturing entities. Specifically, the study sought to determine the influence of operational performance on the relationship between reverse logistics and a firm's competitive advantage. Using correlation cross-sectional survey design, primary data were collected from 175 Kenya Association of Manufacturers (KAM) registered firms through a semi-structured questionnaire. Covariance-based, Structural Equation Modeling (SEM) was used to analyze the data and test the study hypothesis. Results from the hypothesis tests revealed that operational performance significantly mediates the association linking reverse logistics and a firm's competitive advantage. The study confirmed that when resources are mobilized uniquely, they create comparative advantage consequently leading to competitive advantage. The study recommends that implementation
\end{abstract}


of reverse logistics should be guided by a process that requires identifying the uniqueness of resources the organization has and strategically utilizing these resources in a manner that builds comparative advantage. Policymakers within the manufacturing sector in Kenya should improve the regulatory framework to upscale application of reverse logistics strategies in a manner that improves operational performance. Based on the limitations of the study, areas for further research have been suggested.

Keywords: Reverse Logistics, Operational Performance, Covariance based SEM. Manufacturing firms in Kenya

\section{Introduction}

Environmental concerns presently have led manufacturing firms to redesign their processes in order to have environmentally friendly manufacturing (Govindan, Soleimani \& Kannan, 2015; Prakash, Barua \& Pandya, 2015). As a result, manufacturers and consumers alike are required to dismantle used products into their constituent parts for reuse, recycling, or safe disposal (Sheth, Sethia \& Srinivas, 2011). Reverse logistics is concerned with moving "end of useful life" goods from consumers to manufacturers so as to recapture value or ensure environmentally friendly disposal (Stock, 1992). In the process of strategically managing the product returns process, firms also aim at gaining operational efficiency (Stock, Speh \& Shear, 2006). Gaining operational efficiency by strategically managing product returns can lead to improving a firm's competitory position.

According to Stock (1992) reverse logistics entails logistics activities relating to recycling and disposal of waste and hazardous materials management. Reverse logistics as a process systematically involves the costeffective planning, implementation, and control of the efficient movement of raw materials, partly completed and finished products, and the associated information from their usage locale back to their origin either to reclaim value or for apt disposal (Rogers \& Tibben-Lembke, 1999). Environmental concerns, effects of climate change, scarcity of manufacturing raw materials and technological advancements have increased attention and focus on reverse logistics (Blumberg, 1999; Dias \& Braga Jr., 2016). Factors leading to increased volumes of reverse product flow include; lowering of product quality; liberal returns polices; buyer's changing preferences; increased internet product purchases; and shortened product life cycles (Bernon \& Cullen, 2007; Ravi \& Shankar, 2015). The strategies proposed to implement reverse logistics programs include outsourcing, collaborations, adopting green strategies or implementing reverse logistics from a product-life cycle approach using closed-loop supply strategy. Outsourcing enables a firm to concentrate on its core capabilities, achieve higher flexibility and transfer risk to a third 
party (He \& Wang, 2005; Moghaddam, 2015; Hsu, Tan \& Mohamad-Zailani, 2016). Collaborations led by industry associations or governments can integrate reverse logistics operations for firms in an industry (Hung-Lau \& Wang, 2009). Adopting green strategies such as reuse, recycle and remanufacture helps in "greening" the supply chain (Rogers \& TibbenLembke, 2001; Rao \& Holt, 2005). Finally, implementing reverse logistics using the product-life cycle approach allows for the recreation of value through the closed-loop supply chain (Closs, Speier \& Meacham, 2011; Govindan et al., 2015; Sangwan, 2017).

Competitive advantage refers to the unique ability in a firm that enables it to have higher returns than its competitors (Kim \& Hoskisson, 2015). To have competitive advantage firms need to offer distinct value propositions using customized value chains with unique trade-offs from those of its competitors (Porter, 2008). Building the product returns process to generate new market opportunities creates competitive advantage by attracting new clients and retaining existing ones (Jayaraman \& Luo, 2007). Reverse logistics has facilitated the generation of competitive advantage through influencing the purchasing behavior of customers based on how the product returns are handled (Stock et al., 2006). Barney (1991) identified properties that permit the sustainable realization of competitive advantage to include resource value, the rarity of the resource, an imperfectly imitable resource, an imperfectly mobile resource and a non-substitutable resource. Markley and Davis (2007) suggested customer loyalty, waste reduction, revenue increase, market share, and brand recognition as indices for measuring competitive advantage. Jayaraman and Luo (2007) similarly suggested customer relations, brand image and reputation as ways of assessing a firm's competitive advantage.

Operational performance is the degree to which predetermined goals and targets are being accomplished using a process-oriented approach that measures' productivity of resources and the quality of outputs and outcomes of products and services (Shaw, 2003). Operational performance identifies and measures attributes that relate outcomes of firm processes to performance such as defect rates, production cycle time, and inventory turnover. Operational performance measurement is an on-going process of establishing, monitoring and pro-actively taking corrective action towards achieving organizational goals, efficiently and effectively (Carter, Kale \& Grimm, 2000). Various indices exist for measuring operational performance. Operational performance can be measured in terms of defect rate per item, the extent of customer complaints, degree of waste, mean- time failure rate, client query time, requisition lead time, throughput rate, and efficiency level (Slack, Chambers \& Johnston, 2010). Studies have shown that the major operational performance dimensions include; cost, time/speed, operations flexibility, 
dependability and quality (Carter et al., 2000; Brah \& Ying-Lim, 2006; De Souza \& Brito, 2011; Chavez, Gimenez, Fynes, Wiengarten \& Yu, 2013).

Although manufacturing firms globally are increasingly recognizing the importance of conserving the environment, implementation of strategies such as reverse logistics aimed at reducing environmental effect has been slow (Hung-Lau \& Wang, 2009). This is because manufacturing firms have information systems tailored to optimize forward logistics but similar systems for implementing reverse logistics have persisted at the planning stage. Similarly the development of asset value recovery systems is also at its infancy (Dekker, Fleischmann, Inderfurth \& van Wassenhove, 2013). Reverse logistics requires additional infrastructure such as warehousing space, additional materials handling equipment and transportation vehicles, a factor which not many firms are willing to invest in (Rogers, Banasiak, Brokman, Johnson \& Tibben-Lembke, 2002). Further developing accurate demand forecasts for reverse logistics is more intricate compared to forecasting for forward logistics as a consequence of complexities of tracking defectives. Currently most organizations tend to control product return processes at the individual business unit level and not as a supply chain. Finally the increasing volume of returns greatly exceeds the capacity of business units to manage reverse logistics effectively (Genchev, Glenn-Richey \& Gabler, 2011).

In spite of Kenya's position in East Africa as the most industrially developed country, the manufacturing field in Kenya is not dominant compared to the service and agricultural sectors (KAM, 2018). Growth in the manufacturing sector stood at $3.5 \%$ in 2016. Overall, investments in the manufacturing sector stood at Kshs. 277.4 billion in 2016 with 300,900 persons in formal employment representing $11.8 \%$ of the formal jobs in the country (Kenya National Bureau of Statistics (KNBS), 2017). Further the manufacturing sector contributed $11.8 \%, 11.0 \%, 10.7 \%, 10.0 \%$ and $10.3 \%$ to GDP in the years 2012, 2013, 2014, 2015 and 2016 respectively. As a consequence of environmental concerns and climate change, legislation requiring manufacturers to be environmentally conscious have been developed. Through the Environmental Management and Co-ordination Act (EMCA) No.8 of 1999, Kenya established the National Environmental Management Authority (NEMA) to be the government's arm mandated to implement policies concerning the environment. Similarly through the Kenya Green Economy Strategy and Implementation Plan (K-GESIP), Kenya is adopting various green economy approaches and policies (KNBS, 2017). Despite these, uptake of strategies to mitigate environmental effects among manufacturing firms has been slow with firms being more profit-oriented (World Bank, 2016).

Manufacturing firms in Kenya in their quest to gain competitive advantage have not harnessed the potential of implementing reverse logistics 
programs. The main reason is that developing and implementing such a program has been considered to be a tedious process because of the complexities in developing demand forecasts for reverse logistics and capital requirements for additional infrastructure (Rogers et al., 2002). Similarly, a lack of information systems and asset recovery systems to support informed decision making while developing reverse logistics programs further complicates implementation (Dekker et al., 2013). The Kenyan manufacturing sector has also witnessed the exploitation of the weak institutional mechanisms for enforcing environmental legislation despite initiatives such as K-GESIP (World Bank, 2016). Only until recently have we seen research on reverse logistics in the African context (Somuyiwa \& Adebayo, 2014; Kwateng, Debrah, Parker, Owusu \& Prempeh, 2014; Meyer, Niemann, Mackenzie \& Lombaard, 2017). To account for differences across contexts and due to the prominence of developing economies in global business more research on reverse logistics needs to be done in Africa.

\section{Literature Review}

This research was anchored on the resource advantage theory of competition which posits that organizations gain competitive advantage through marshaling comparative advantage internally (Hunt \& Morgan, 2005). Accumulation of resources internal to the organization rather than the external environment should influence competitive strategy (Amit \& Shoemaker, 1993). From the theory, the resource selection process determines how competition for comparative advantage is gained such that the organization is viewed as the transmissible unit of selection (Conner, 1991). Each organization has unique resources that become a comparative advantage source leading to advantageous opportunities in the market. Such resources provide long-term competitive advantage (Barney, 1991). The theory also recognizes innovation as endogenous to the organizational processes within a firm's competitive environment (Hunt \& Madhavaram, 2012). Despite these, the theory becomes relevant in understanding how operational performance affects reverse logistics and competitive advantage by explaining resource relationships within organizations as they seek to gain comparative advantage. The theory further establishes a framework for interrogating how reverse logistics associated capabilities and outcomes impact a firm (Hunt \& Morgan, 2005). Stock et al. (2006) established that reverse logistics programme achievement was influenced by how resources are committed by management. Firms' gain comparative advantage when resources in their control help to generate and implement strategies resulting in highly efficient and effective operations (Barney, 1991).

A key assumption has been that reverse logistics strategies facilitate sustenance of future generations to fulfill their needs by holding present 
generations environmentally accountable to all shareholders including the number one shareholder, planet earth (Sheth et al, 2011; Dias \& Braga Jr., 2016; Sangwan, 2017). Such strategies are opined to create effective and efficient utilization of a firm's resources thereby legitimizing environmental effects on planet earth at a macro level and providing operational performance gains for firms at a micro-level (Closs et al., 2011; Ravi \& Shankar 2015). Studies have argued for an association linking reverse logistics and the generation of competitive advantage without considering the effect of extraneous variables to this relationship (Stock, 2001; Huang \& Yang, 2014). Further, although scholars have argued for a relationship between operational performance and competitive advantage Oral and Yolalan (1990), Voss, Åhlström and Blackmon (1997) and Carter et al. (2000) this was not from a reverse logistics perspective. Yet, reverse logistics practices have capacity to reduce clients' risk when purchasing products and add value to the customer (Russo \& Cardinali, 2012). Rogers and Tibben-Lembke (2001) opined that reverse logistics programmes can assist a firm to minimize product returns by identifying problem areas and defect patterns through its value system. De Brito, Flapper and Dekker (2005) argued that such a value system has either direct (financial) or indirect (non-financial) benefits resulting in improved competitiveness of the firm. Reverse logistics and a firm's competitory position therefore have a relationship contingent on achieving internal operational proficiency but the strength of the relationship is not known to have been investigated before. Based on the above the researcher hypothesized as follows

Operational performance has no significant mediating influence on the relationship between reverse logistics and a firm's competitive advantage.

\section{Research Methodology}

The study sought to deploy a correlation cross-sectional survey. Correlation research aims at indicating the direction, extent and nature of observed relationships (Zikmund, Babin, Carr \& Griffin, 2013). The study was cross-sectional because data was collected over a single duration. Secondly, cross-sectional research also permitted the creation of heterogeneous population clusters in understanding the underlying group characteristics.

The population of this study consisted of all manufacturing firms in Kenya. The researcher established that KAM has the most comprehensive listing of manufacturing firms in Kenya. As at 30th June 2018 there were 903 firms registered as KAM members in the manufacturing sector. KAM membership was considered appropriate for this study because the association encourages members to have a reuse, reduce and recycling policy. The association also encourages partner organizations to work closely with NEMA 
in implementing environmental management activities. KAM has an annual Energy Management Award (EMA) that recognizes firms' efforts towards energy conservation. These efforts reflect on efforts towards implementation of reverse logistics practices. The sample size was 340 manufacturing firms in Kenya after taking into account a non-response factor of 0.8 based on similar studies (Mellat-Parast \& Spillan, 2014; O'Cass \& Viet, 2007). The study sought to use proportionate stratified random sampling based on the manufacturing sub-sectors in the KAM directory and the number of firms in each sub-sector. Proportionate stratified random sampling minimizes sampling bias where the researcher can mutually exclusively classify members of the population. Figure 1 below provides the specific path diagram for the relationship between the latent constructs of reverse logistics, operational performance and competitive advantage.

Figure 1 suggested that operational performance mediated the association of reverse logistics with competitive advantage. Reverse logistics represented in the diagram as RevLog had outsourcing, collaborative enterprising, green strategies and the product life cycle each of these represented by the rectangular nodes RLOS1, RLCE1, RLGS1 and RLPLCA1 respectively in the diagram. Competitive advantage represented as CompAdv was measured using customer loyalty, market share, brand recognition, waste reduction and revenue increase. These were diagrammatically represented using the rectangular nodes CACL1, CAMS1, CABR1, CAWR1 and CARI1 respectively. Operational performance represented in the diagram as OprPerf was operationalized using per unit variable cost, order fill rate, number of product lines, machine availability and leadtime represented as rectangular nodes labeled, OPUVC1, OPOFR1, OPPL1, OPDMA1 and OPLTA1 respectively. 


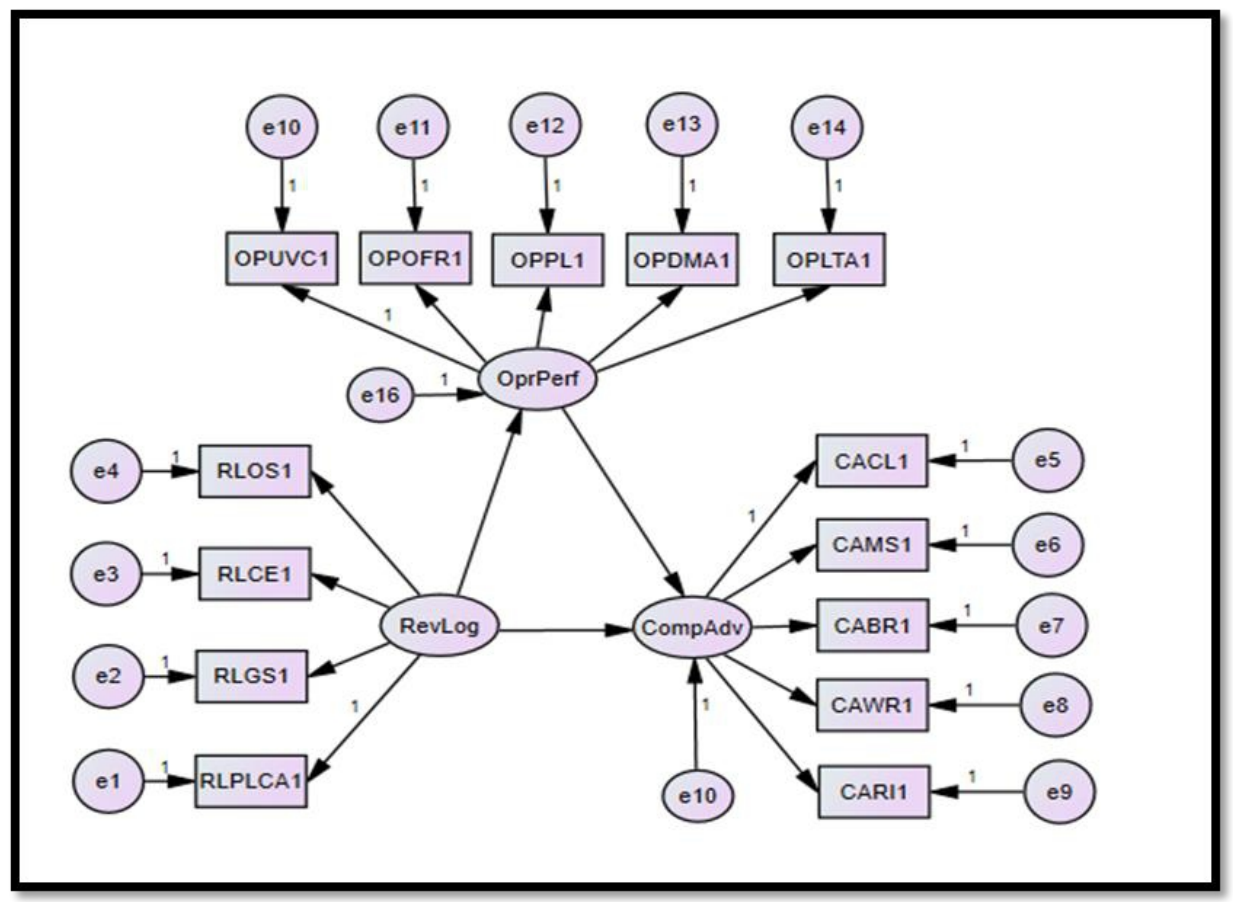

Figure 1. Path Diagram linking Reverse Logistics, Operational Performance and Competitive Advantage

\section{Results}

A total of 340 questionnaires were circulated to respondents out of which 175 were filled and returned. This represented a response rate of 44.4\%. Although high response rates ( $>70 \%$ ) are preferable Mugenda and Mugenda (1999) other studies have shown that results from studies with response rates as low as $20 \%$ have no statistically significant difference with those of high response rates (Keeter, Kennedy, Dimock, Best \& Craighill, 2006: Curtin, Presser \& Singer, 2000). KMO and Bartlett tests were conducted using the latent constructs of reverse logistics, operational performance and competitive advantage. The KMO test yielded a value of 0.919 which is $>0.7$. Sphericity test gave a p-value of 0.000 which is $<0.05$. This means that conducting confirmatory factor analysis will produce statistically reliable factors and results. It also means that it is possible to conduct dimension reduction for both the measured and structured model with reverse logistics operational performance and competitive advantage. Table 1 below provides details of the Cronbach's alpha measuring the internal reliability of the questionnaire items for reverse logistics. 
Table 1. Cronbach Alpha Results for Reverse Logistics Questionnaire Items

\begin{tabular}{llc}
\hline & \multicolumn{1}{c}{ Variables } & Cronbach Alpha \\
\hline 1 & Outsourcing & 0.708 \\
2 & Collaborative Enterprise & 0.716 \\
3 & Green Strategies & 0.729 \\
4 & Product Life Cycle Approach & 0.707 \\
\hline
\end{tabular}

Based on table 1 above the Cronbach alpha coefficient to check whether the questionnaire items were actually measuring the latent constructs for reverse logistics ranged between 0.707 and 0.729. Communalities were then assessed using Principal Component Analysis (PCA) in order to determine how much of the variance in each of the latent constructs for reverse logistics were explained by the undeleted questionnaire items (Field, 2013). Communality coefficient ranged between 0.810 to 0.968 . This means that the undeleted questionnaire items explained between $81.0 \%$ and $96.8 \%$ of the variance of the respective latent construct. Since these values are $>0.3$ it indicates that latent constructs have sufficient explanatory power on the latent variables. Cronbach alpha coefficient to check whether the latent constructs were actually measuring the latent variables ranged between 0.897 and 0.943. These indicate sufficient internal consistency between the questionnaire items the latent constructs and the latent variables.

The standardized factor loadings for all the latent constructs of reverse logistics, operational performance and competitive advantage were $>0.5$ except for the latent constructs OPUVC1 and CAWR1 which had standardized factor loadings significantly $<0.5$. For this reason they were expunged from the model. To confirm convergent validity Average Variance Extraction (AVE) method was used. Table 2 below reveals AVE computations.

Table 2. Average Variance Extraction results for Reverse Logistics, Operational Performance and Competitive Advantage

\begin{tabular}{lccrrr}
\hline Factor & $<---$ & Component & Loadings & $\begin{array}{c}\text { Squared } \\
\text { Loadings }\end{array}$ & AVE \\
\hline RLPLCA1 & $<---$ & RevLog & 0.622 & 0.387 & 0.841 \\
RLGS1 & $<---$ & RevLog & 0.997 & 0.994 & \\
RLCE1 & $<---$ & RevLog & 0.994 & 0.988 & \\
RLOS1 & $<---$ & RevLog & 0.997 & 0.994 & \\
OPLTA1 & $<---$ & OprPerf & 0.928 & 0.861 & 0.836 \\
OPDMA1 & $<---$ & OprPerf & 0.903 & 0.815 & \\
OPPL1 & $<---$ & OprPerf & 0.888 & 0.789 & \\
OPOFR1 & $<---$ & OprPerf & 0.938 & 0.880 & \\
CARI1 & $<---$ & CompAdv & 0.998 & 0.996 & \\
CABR1 & $<---$ & CompAdv & 0.848 & 0.719 & \\
CAMS1 & $<---$ & CompAdv & 0.91 & 0.828 & \\
CACL1 & $<---$ & CompAdv & 0.995 & 0.990 & \\
\hline
\end{tabular}


Since the AVE values for reverse logistics, operational performance and competitive advantage are $>0.5$, this indicated good convergent validity. Discriminant validity which examines how constructs perceived not to be theoretically associated are indeed not associated was measured by comparing the AVE with the Maximum Shared Variance (MSV). Table 3 below summarizes the MSV squared loadings for the reverse logistics, operational performance and competitive advantage latent variable.

Table 3. Maximum Shared Variance results Reverse Logistics, Operational Performance and Competitive Advantage

\begin{tabular}{lllrr}
\hline Component & $<->$ & Component & Loadings & Squared Loadings \\
\hline RevLog & $<->$ & OprPerf & 0.691 & 0.477 \\
RevLog & $<->$ & CompAdv & 0.935 & 0.874 \\
OprPerf & $<->$ & CompAdv & 0.657 & 0.432 \\
\hline
\end{tabular}

Based on table 3 above the square correlation between reverse logistics and operational performance latent variable was 0.477 . This value was $<$ the AVE of reverse logistics latent variable with a coefficient of 0.841 (Table 2). The square correlation linking reverse logistics with competitive advantage latent variables was 0.874 . This value was not significantly > the AVE of reverse logistics latent variable (Table 2). The square correlation between operational performance and competitive advantage latent variables was 0.432 . These values were < the AVE of operational performance latent variable with a coefficient of 0.836 (Table 2). This means that there was evidence to suggest discriminant validity.

Each of the latent constructs forming the reverse logistics variable were aggregated and coefficients that summarize the aggregated data set were calculated. Outsourcing was rated as the most common reverse logistics approach among Kenyan manufacturing firms with a mean of 3.63 and Standard Deviation (StdDev) of 0.51 . The second most common reverse logistics approach was green strategies with a mean of $3.56(\operatorname{StdDev}=0.41)$. The least rated were product life cycle approach and collaborative enterprise both with means of 3.51 (StdDev $=0.58$ and 0.60 respectively). These generally indicate that the respondents generally concurred with the statements moderately but tending towards a large degree. The z-skewness scores were between -0.06 and 0.11 . This generally reflects that the distributions generated from these latent constructs tended to be symmetrical. The z-kurtosis scores were between -1.56 and -0.78. Although this suggests the distributions formed by these latent constructs were mesokurtic but they were tending towards being platykurtic.

Operational performance was measured using four constructs namely; quality, flexibility, dependability and delivery speed. In order to measure quality, order fill rate was used. Flexibility was measured using the number of 
product lines. Dependability was measured using capacity utilization rate of machine and equipment as a proxy indicator. Delivery speed was measured using lead-time. Using the order fill rate, on average the number of items actually delivered to customers in the course of the year stated as a percentage of the total orders stood at $95.20 \%$ and a Coefficient of Variation (CV) of $2.0 \%$. The average number of product-lines among manufacturing firms was $9.47(\mathrm{CV}=36.6 \%)$. Using the capacity utilization rate, on average the number of hours of equipment/machines that were actually available for manufacturing operations in the year stated as a percentage of the hours these equipment/machines are supposed to be available for manufacturing operations was $91.26 \%(\mathrm{CV}=1.3 \%)$. An analysis of the lead-time revealed the mean number of days between order receipt and shipment to the customer was 10.50 days $(\mathrm{CV}=33.7 \%)$. The four constructs used to measure operational performance had z-skewness scores ranging between 0.01 and 0.33 . These scores ranged between \pm 1.96 indicating they were fairly symmetrical. z-kurtosis scores ranged from - 1.33 to - 0.74. These z-kurtosis scores range between \pm 1.96 indicating that the distributions were mesokurtic.

Competitive advantage was measured using four constructs namely; customer loyalty, market share, brand recognition, waste reduction and revenue increase. Customer loyalty was measured using the customer retention rate. Market share was measured using the market share index for each firm in each industry. Brand recognition was measured using the profit margin as a proxy indicator. Revenue increase was measured by subtracting the revenue for last year from those of the previous year and dividing this with the revenue for the previous year to determine the percentage increase. On average the customer retention rate was $91.66 \%(\mathrm{CV}=3.2 \%)$. The mean market share for the manufacturing firms was $17.52 \%(\mathrm{CV}=20.6 \%)$. On average the profit margin for the manufacturing firms was $26.97 \%$ (CV = $25.7 \%$ ) and the average revenue increase for the manufacturing firms was $6.43 \%(\mathrm{CV}=31.6 \%)$. The four constructs used to measure competitive advantage had $\mathrm{z}$-skewness scores ranging between -0.23 and 0.01 indicating symmetrical distributions. Z-kurtosis scores ranged from -1.89 to -1.32 . These z-kurtosis scores range between \pm 1.96 indicating that the distributions are mesokurtic but tended towards being platykurtic.

Kolmogorov-Smirnov test and Shapiro-Wilk test were used for testing of normality (Field, 2013). The results of the Kolmogorov-Smirnov for all the 16 key variables of the study show significance levels with the lowest at 0.058 and the highest $>0.200$. While the Shapiro-Wilk test results for all the $16 \mathrm{key}$ variables show significance levels ranging from 0.069 to 0.348 . Since the $p$ values are $>0.05$ we presume that the distributions generated by the observations for each variable have a normal distribution. Durbin-Watson test statistic was used to test for autocorrelation of the first order. Durbin-Watson 
calculated statistics values ranged from 1.848 to 2.148 . These were all within the acceptance region of 1.788 to 2.212 meaning that serial autocorrelation does not exist at the first order level. The Variance Inflation Factor values for the latent constructs of reverse logistics and operational performance were between 1.088 and 7.178. The corresponding tolerance values ranged between 0.139 and 0.954 indicating the latent constructs were not multicollinearily associated. Reverse logistics latent constructs were tested for heteroscedasticity as independent variables against the respective competitive advantage and operational performance latent constructs as dependent variables. The Koenker calculated test statistics value ranged from 0.062 to 0.494. Similarly operational performance latent constructs were tested for heteroscedasticity as independent variables against the respective competitive advantage latent constructs as dependent variables. The Koenker test calculated statistics value ranged from 0.073 to 0.316 . Since these p-values are $>0.05$ then the variance of the dependent variables given the independent variables is presumed to be constant and therefore there is no heteroscedasticity.

The overall model fit of the measured models was assessed through the absolute, incremental and parsimonious model fitness tests. Table 4 below summarizes the results of the Confirmatory Factor Analysis (CFA) for the measured model for the latent constructs of reverse logistics, operational performance and competitive advantage.

Table 4. Overall Model Fit Results for the Measured Model

\begin{tabular}{lcrrr}
\hline Test & $\begin{array}{c}\text { Decision } \\
\text { Criteria }\end{array}$ & \multicolumn{3}{c}{ Model Result } \\
\hline Chi-Square & & $\frac{\text { RevLog }}{0.319}$ & \multicolumn{1}{c}{ OprPerf } & CompAdv \\
Degrees of & & 1 & 2.050 & 0.122 \\
Freedom & & & & 1 \\
p-value & $>0.05$ & 0.572 & 0.08 & 0.727 \\
GFI & $>0.90$ & 0.999 & 0.983 & 1.000 \\
CFI & $>0.90$ & 1.000 & 0.995 & 1.000 \\
AGFI & $>0.90$ & 0.989 & 0.916 & 0.996 \\
NFI & 0.8 NFI & 1.000 & 0.993 & 1.000 \\
& 1.00 & & & \\
TLI & $>0.90$ & 1.003 & 0.986 & 1.005 \\
RMSEA & $<0.08$ & 0.000 & 0.101 & 0.000 \\
CMIN/DF & $<5$ & 0.319 & 2.525 & 0.122 \\
\hline
\end{tabular}

From the results absolute fitness was assessed using chi-square value, p-value, Root Mean Square Error of Approximation (RMSEA) and Goodness of Fit Index (GFI) where the chi-square value ranged between 5.050 and 0.122 indicating they were small. P-value ranged between 0.08 and 0.881 showing that they were $>0.05$. RMSEA was $<0.08$ for the latent constructs of reverse 
logistics and competitive advantage. The RMSEA value for the latent constructs of operational performance was 0.101 which was not significantly $>0.08$. GFI values ranged between 0.983 and 1.000 indicating they were > 0.90. These suggest that the measured models had good absolute fit.

Incremental model fitness was assessed using Adjusted Goodness of Fit Index (AGFI), Comparative Fit Index (CFI), Normed Fit Index (NFI) and Turker Lewis Index (TLI). AGFI values ranged between 0.916 and 0.996 . These were all $>0.90$. CFI values were between 0.995 and 1.000 indicating they were all $>0.90$. The NFI values ranged between 0.993 and 1.000 showing they were between the threshold values, $0.8<\mathrm{NFI}<1.00$. TLI values were ranging between 0.986 and 1.005 showing they were $>0.9$. These values indicate that all the measured models for the latent constructs had good incremental fit. Chi-Square/Degrees of Freedom (CMIN/DF) values ranged between 0.122 and 2.525 . The minimum discrepancy ratio was expected to be $<5$. These indicated that measured models for the latent constructs had good parsimonious fit. Table 5 below summarizes model fitness results for the structured model.

Table 5. Overall Model Fit Results for the Structured Model

\begin{tabular}{ccr}
\hline Test & Decision Criteria & \multicolumn{2}{c}{ Model Result } \\
\hline Chi-Square & & 201.009 \\
Degrees of Freedom & $>0.90$ & 44 \\
GFI & $>0.90$ & 0.827 \\
CFI & $>0.90$ & 0.962 \\
AGFI & $0.8<$ NFI $<1.00$ & 0.694 \\
NFI & $>0.90$ & 0.952 \\
TLI & $<0.08$ & 0.943 \\
RMSEA & $<5$ & 0.154 \\
CMIN/DF & & 4.568 \\
\hline
\end{tabular}

For the structured model chi-square square value of 201.009, 44 degrees of freedom, RMSEA of 0.154 and a GFI of 0.827 , indicated the model had good absolute fit. The AGFI, CFI, NFI and TLI had coefficients of 0.694 , $0.962,0.952$ and 0.943 . NFI was within the range between 0.80 and 1.00 . CFI and TLI were $>0.9$. AGFI was not significantly low. This model therefore exhibited a moderately good incremental fit. Parsimonious model fitness was assessed using CMIN/DF which was 4.568, suggesting a good parsimonious fit. Figure 3 below reveals the overall structural equation model among reverse logistics, operational performance and competitive advantage. 


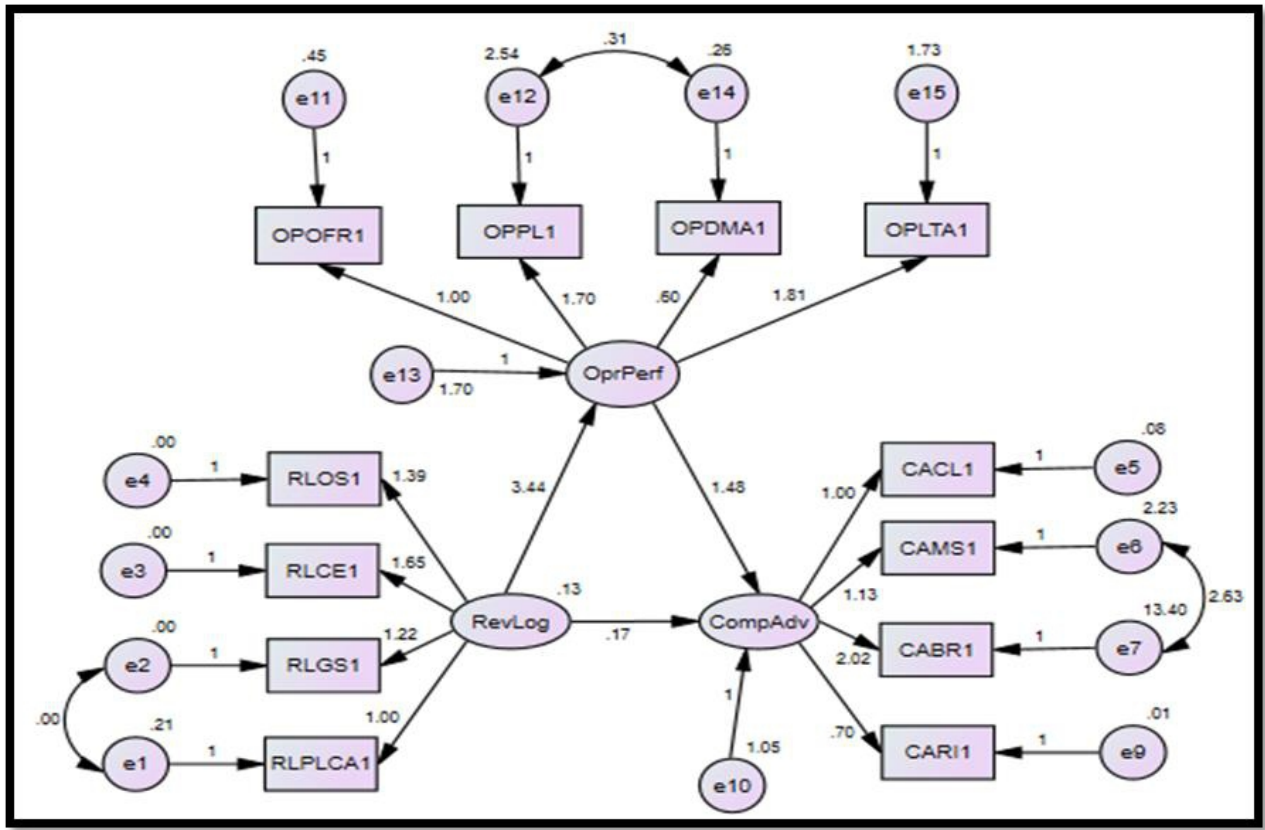

Figure 2. Unstandardized Structural Equation Model for Reverse Logistics, Operational Performance and Competitive Advantage

To assess the extent to which the unstandardized factor loadings are statistically significant, the standard error of the estimates, the critical ration and $p$-values were calculated. The critical values were all $>1.96$ with $p$-values $<0.05$ suggesting that the factor loadings are statistically significant. The unstandardized factor loadings were standardized to determine the degree to which the factors load on the components. The standardized factor loadings ranged between 0.622 and 0.998 . This indicated a high loading of the factors on the components. Finally an analysis of whether the latent variables had a statistically significant relationship on the structured model was done. The results indicated that the factor loadings for the structured relationships between reverse logistics and operational performance (0.69) and between operational performance and competitive advantage (0.92) were statistically significant. However the factor loadings for the structured relationships between reverse logistics and competitive advantage (0.02) were statistically insignificant.

The Common Latent Factor (CLF) for each of the variables was 0.00 . This therefore gives a Common Method Variance (CMV) of 0.0000 which is $<0.5$ for each of the variables. Further the difference between the standardized regression weights without the CLF and with CLF was $<0.20$ therefore it confirmed that it will not be necessary to include the common method latent variable while performing hypothesis testing. The unstandardized structural equation model for the relationship between reverse logistics and competitive 
advantage had a path co-efficient of 0.17 . The $\mathrm{p}$-value for the reverse logistics association with competitive advantage was $<0.001$ in the direct relationship but changed to 0.670 in the mediating relationship, while the p-value between reverse logistics and operational performance and between operational performance and competitive advantage were both $<0.001$. Consequently the null hypothesis was rejected therefore operational performance had significant mediating influence on the relationship between reverse logistics and a firm's competitive advantage with a complete mediation effect.

\section{Discussion}

Theoretical underpinning from the resource advantage theory of competition and literature review led to the opinion that operational performance mediates the association linking reverse logistics implementation and firms gaining competitive advantage. The result in this study indicated there was complete mediation of operational performance on the association linking reverse logistics and competitive advantage.

This result is in congruence with the results from other studies (Prakash et al., 2015; Dias \& Braga Jr., 2016). These studies generally assumed that mobilizing resources in a unique way led to the creation of comparative advantage which in turn resulted in the creation of competitive advantage but with minimal empirical confirmation. This study therefore made a positive contribution to the link between reverse logistics programme achievement, gaining operational competence and the achievement of competitive advantage.

The theoretical basis behind the mediation relationship between reverse logistics, operational performance and competitive advantage was founded on the resource advantage theory of competition. The theory posited that, harnessing unique resources assists firms to gain unique internal competencies, which enable firms' to build competitive advantage at the marketplace (Barney, 1991). The study revealed that there exists a positive and significant association linking reverse logistics implementation and operational performance in creating competitive advantage. This supported the proposition that the resource selection process determines how competition for comparative advantage is gained (Conner, 1991; Hunt \& Morgan, 2005).

Further operational performance strongly dominated the significant reverse logistics interaction with competitive advantage. This meant that when resources are mobilized in a unique way, they create comparative advantage which then has the outcome of creating competitive advantage (Prakash et al., 2015; Dias \& Braga Jr., 2016). This means that for manufacturing firms in Kenya the better the resource selection process the higher the chances of gaining competitiveness through the gains of comparative advantage (Conner, 
1991; Hunt \& Morgan, 2005). This reveals that gaining operational competence is linked to the achievement of competitive advantage.

\section{Summary and Conclusion}

The study observed that mobilization of resources in a distinctive way creates operations efficiency and this leads to achieving competitive advantage. This is propounded in literature (Prakash \& Barua, 2015; Hunt \& Madhavaram, 2012; Dias \& Braga Jr., 2016). Therefore the study contributes to knowledge by suggesting that comparative advantage is improved by having a better resource selection process. This in turn improves competitiveness (Conner, 1991; Hunt \& Morgan, 2005). This reveals that achievement of competitive advantage is dependent on gaining operational competence even from a reverse logistics perspective.

\section{Implications}

The study adds empirical evidence to the interaction between reverse logistics and competitive advantage. Specifically, the study demonstrates that competitive advantage is created by implementing reverse logistics using outsourcing, collaborative enterprising, green strategies and closed-loop supply chain approaches. This is reflective of the ideas discussed by Hsu, Tan and Mohamad-Zailani (2016), Hung-Lau and Wang (2009), Rao and Holt (2005) and Govindan et al. (2015) respectively.

The study established that operational performance strongly influenced the reverse logistics link with competitive advantage. Manufacturing firms in Kenya should implement resource selection processes that increase the chances of gaining comparative advantage and hence competitiveness. This implementation should be guided by a process that requires identifying the uniqueness of resources the organization has and strategically placing these resources in a manner that builds comparative advantage (Hunt \& Madhavaram, 2012).

The study obligates policy developers in the manufacturing sector, to make policies that leverage the influence of reverse logistics on competitive advantage. These should promote outsourcing reverse logistics to return's service providers He and Wang (2005), formation of industry associations or strategic alliances to facilitate reverse logistics activities Hung-Lau \& Wang (2009), adoption of reuse, recycle and remanufacture policies Rogers and Tibben-Lembke (2001) and developing closed-loop supply chains (Govindan et al., 2015; Sangwan, 2017).

\section{Limitations and Suggestions for Further Research}

Reverse logistics was measured using perceptual data. Objective data does not change over time and sectoral variations are easier to control within 
the models. Objective data therefore tends to have better explanatory power among the variables in the model. Future researchers should consider operationalizing variables in hypothesized relationships using direct measures of performance especially where covariance-based SEM is the method to be used for data analysis.

\section{Acknowledgement}

We are indebted to Rose Mutwiwa and Allan Kimonge for their immeasurable support in the coordination of the distribution of the data collection instrument and subsequent respondents follow-up. In closing, we also wish to appreciate each individual survey respondent and their respective organization for their worthy contributions.

\section{References:}

1. Amit, R., \& Shoemaker, P. J. H. (1993). Strategic assets and organizational rents. Strategic Management Journal, 14 (1), 33-46.

2. Barney, J. (1991). Firm resources and sustained competitive advantage. Journal of Management, 17(1), 99-120.

3. Bernon, M., \& Cullen, J. (2007). An integrated approach to managing reverse logistics. International Journal of Logistics: Research and Applications, 10(1), 41-56.

4. Blumberg, D. F. (1999). Strategic examination of reverse logistics \& repair service requirements, needs, market size, and opportunities. Journal of Business Logistics, 20(2), 141-159

5. Brah, S. A., \& Ying-Lim, H. (2006). The effects of technology and TQM on the performance of logistics companies. International Journal of Physical Distribution \& Logistics Management, 36(3), 192209.

6. Carter, C. R., Kale, R., \& Grimm, C. M. (2000). Environmental purchasing and firm performance: an empirical investigation. Transportation Research Part E: Logistics and Transportation Review, 36(3), 219-228.

7. Chavez, R., Gimenez, C., Fynes, B., Wiengarten, F., \& Yu, W. (2013). Internal lean practices and operational performance: The contingency perspective of industry clockspeed. International Journal of Operations \& Production Management, 33(5), 562-588.

8. Closs, D. J., Speier, C., \& Meacham, N. (2011). Sustainability to support end-to-end value chains: the role of supply chain management. Journal of the Academy of Marketing Science, 39(1), 101-116.

9. Conner, K. R. (1991). A historical comparison of resource-based theory and five schools of thought within industrial organization 
economics: do we have a new theory of the firm?. Journal of Management, 17(1), 121-154.

10. Curtin, R., Presser, S., \& Singer, E. (2000). The effects of response rate changes on the index of consumer sentiment. Public opinion quarterly, 64(4), 413-428.

11. De Brito M.P., Dekker R., Flapper S.D.P. (2005) Reverse logistics: A review of case studies. In B. Fleischmann \& A. Klose (Eds.), Distribution logistics. Lecture notes in economics and mathematical systems, 544, (pp. 243-281). Berlin, Germany: Springer Science \& Business Media.

https:/doi:10.1007/978-3-642-17020-1_13

12. De Souza M. P. L., \& Brito, L. A. L. (2011). Supply chain management measurement and its influence on operational performance. Journal of Operations and Supply Chain Management, 4(2), 56-70.

13. Dekker, R., Fleischmann, M., Inderfurth, K., \& van Wassenhove, L. N. (Eds.). (2013). Reverse logistics: Quantitative models for closedloop supply chains. Berlin, Germany: Springer Science \& Business Media.

14. Dias, K. T., \& Braga Jr., S. S. (2016). The use of reverse logistics for waste management in a Brazilian grocery retailer. Waste Management \& Research, 34(1), 22-29.

15. Field, A. (2013). Discovering statistics using IBM SPSS statistics. Thousand Oaks, Carlifonia, USA: Sage.

16. Genchev, S. E., Glenn-Richey, R., \& Gabler, C. B. (2011). Evaluating reverse logistics programs: A suggested process formalization. The International Journal of Logistics Management, 22(2), 242-263.

17. Govindan, K., Soleimani, H., \& Kannan, D. (2015). Reverse logistics and closed-loop supply chain: A comprehensive review to explore the future. European Journal of Operational Research, 240(3), 603-626.

18. He, X., \& Wang, J. X. (2005). An overview of reverse logistics. International Journal of Plant Engineering and Management, 10(2), 120-124.

19. Hsu, C. C., Tan, K. C., \& Mohamad-Zailani, S. H. (2016). Strategic orientations, sustainable supply chain initiatives, and reverse logistics: Empirical evidence from an emerging market. International Journal of Operations \& Production Management, 36(1), 86-110.

20. Huang, Y. C., \& Yang, M. L. (2014). Reverse logistics innovation, institutional pressures and performance. Management Research Review, 37(7), 615-641.

21. Hung-Lau, K., \& Wang, Y. (2009). Reverse logistics in the electronic industry of China: a case study. Supply Chain Management: An International Journal, 14(6), 447-465. 
22. Hunt, S. D., \& Morgan, R. M. (2005). The resource-advantage theory of competition. Review of Marketing Research, 1(4), 153-206

23. Hunt, S. D., \& Madhavaram, S. (2012). Managerial action and resource-advantage theory: Conceptual frameworks emanating from a positive theory of competition. Journal of Business \& Industrial Marketing, 27(7), 582-591.

24. Jayaraman, V., \& Luo, Y. (2007). Creating competitive advantages through new value creation: a reverse logistics perspective. The Academy of Management Perspectives, 21(2), 56-73.

25. Keeter, S., Kennedy, C., Dimock, M., Best, J., \& Craighill, P. (2006). Gauging the impact of growing nonresponse on estimates from a national RDD telephone survey. International Journal of Public Opinion Quarterly, 70(5), 759-779.

26. Kenya Association of Manufacturer's Directory. (2018). Annual Report. Retrieved from http:// www.manufacturersandexportersdirectory.co.ke.

27. Kenya National Bureau of Statistics. (2017). Economic Survey. Retrieved from http://www.knbs.or.ke.

28. Kim, H., \& Hoskinsson, R.E. (2015). A resource environment view of competitive advantage. Emerging Economies and Multinational Enterprises, 28, 95-140.

29. Kwateng, K. O., Debrah, B., Parker, D. V., Owusu, R. N., \& Prempeh, H. (2014). Reverse logistics practices in pharmaceutical manufacturing industry: experiences from Ghana. Global Journal of Business Research, 8(5), 17-26.

30. Markley, M. J., \& Davis, L. (2007). Exploring future competitive advantage through sustainable supply chains. International Journal of Physical Distribution \& Logistics Management, 37(9), 763-774.

31. Mellat-Parast, M., \& Spillan,E. J. (2014). Logistics and supply chain process integration as a source of competitive advantage: An empirical analysis. The International Journal of Logistics Management, 25(2), 289-314.

32. Moghaddam, K. S. (2015). Fuzzy multi-objective model for supplier selection and order allocation in reverse logistics systems under supply and demand uncertainty. Expert Systems with Applications, 42(15-16), 6237-6254.

33. Mugenda, O. M., \& Mugenda, A. G. (1999). Research methods: Quantitative and qualitative approaches. Acts press.

34. O'Cass, A., \& Viet, N. L. (2007). Market orientation versus innovative culture: two routes to superior brand performance. European Journal of Marketing, 41(7/8), 868-887. 
35. Oral, M., \& Yolalan, R. (1990). An empirical study on measuring operating efficiency and profitability of bank branches. European Journal of Operational Research, 46(3), 282-294.

36. Porter, M. E. (2008). On competition. Cambridge, Massachusetts, USA: Harvard Business Press.

37. Prakash, C., Barua, M. K., \& Pandya, K. V. (2015). Barriers analysis for reverse logistics implementation in Indian electronics industry using fuzzy analytic hierarchy process. Procedia-Social and Behavioral Sciences, 189(2015), 91-102.

38. Rao, P., \& Holt, D. (2005). Do green supply chains lead to competitiveness and economic performance?. International Journal of Operations \& Production Management, 25(9), 898-916.

39. Ravi, V., \& Shankar, R. (2015). Survey of reverse logistics practices in manufacturing industries: an Indian context. Benchmarking: An International Journal, 22(5), 874-899.

40. Rogers, D. S., Banasiak, K., Brokman, K., Johnson, T., \& TibbenLembke, R. (2002, January). Reverse logistics challenges. Paper presented at the 2001 Annual Conference Proceedings.

41. Rogers, D. S., \& Tibben-Lembke, R. S. (1999). Going backwards: reverse logistics trends and practices (Vol. 2). Pittsburgh, Pennsylvania, USA: Reverse Logistics Executive Council.

42. Rogers, D. S., \& Tibben-Lembke, R. S. (2001). An examination of reverse logistics practices, Journal of Business Logistics, 22(2), 129149.

43. Russo I., \& Cardinali S. (2012). Product returns and customer value: A footware industry case. In H. Jodlbauer, J. Olhager \& R. Schonberger (Eds.), Modelling value. Contributions to management science. (pp 79-97). Physica-Verlag HD https:/doi:10.1007/978-3-7908-2747-7_5

44. Sangwan, K. S. (2017). Key activities, decision variables and performance indicators of reverse logistics. Procedia CIRP, 61(2017), 257-262.

45. Shaw, T. (2003). Performance measures of operational effectiveness for highway segments and systems (Vol. 311). Transportation Research Board.

46. Sheth, J. N., Sethia, N. K., \& Srinivas, S. (2011). Mindful consumption: A customer centric approach to sustainability. Journal of the Academy of Marketing Science, 39(1), 21-39.

47. Slack, N., Chambers, S., \& Johnston, R. (2010). Operations management. (6th ed.). Essex, England: Pearson Education.

48. Somuyiwa, A. O., \& Adebayo, I. T. (2014). Empirical study of the effect of reverse logistics objectives on economic performance of food 
and beverages companies in Nigeria. International Review of Management and Business Research, 3(3), 1484-1493.

49. Stock, J. R. (1992). Reverse logistics: White paper. Council of Logistics Management.

50. Stock, J. R. (2001). The 7 deadly sins of reverse logistics. Material Handling Management, 56(3), 5-11.

51. Stock, J., Speh, T., \& Shear, H. (2006). Managing product returns for competitive advantage. MIT Sloan Management Review, 48(1), 57-62.

52. Voss, C. A., Åhlström, P., \& Blackmon, K. (1997). Benchmarking and operational performance: Some empirical results. International Journal of Operations \& Production Management, 17(10), 1046-1058.

53. World Bank. (2016). Economic Update: Kenya's Ecconomy Strong in a Challenging Global Environment. Retrieved from http://www.worldbank.org/en/country/ kenya/ publication

54. Zikmund, W. G., Babin, B. J., Carr, J. C., \& Griffin, M. (2013). Business research methods (9th ed.). Boston, Massachusetts, USA: Cengage Learning. 